\title{
Evolution of Dislocation Loops in AL-6XN Stainless Steels Irradiated by Hydrogen Ions
}

\author{
Zhong-Cheng Zheng ${ }^{1} \cdot$ Yan-Xia Yu ${ }^{1} \cdot$ Wei-Ping Zhang ${ }^{1} \cdot$ Zhen-Yu Shen $^{1} \cdot$ Feng-Feng Luo $^{1,2} \cdot$ Li-Ping Guo ${ }^{1} \cdot$ \\ Yao-Yao $\operatorname{Ren}^{3} \cdot$ Rui Tang ${ }^{4}$
}

Received: 14 March 2016/Revised: 29 June 2016/Published online: 11 October 2016

(C) The Chinese Society for Metals and Springer-Verlag Berlin Heidelberg 2016

\begin{abstract}
AL-6XN stainless steels, one of the candidate structure materials for supercritical water-cooled reactor, were irradiated from 0.5 to $5 \mathrm{dpa}$ using $100 \mathrm{keV} \mathrm{H}_{2}{ }^{+}$ions at 290 and $380{ }^{\circ} \mathrm{C}$. Microstructures were characterized by transmission electron microscopy (TEM). Dislocation loops were the dominant radiation-induced defects. All the dislocation loops had $1 / 3<111>$ type Burgers vector. Number density and size of the loops have been measured. Nucleation and evolution of dislocation loops were also investigated. Voids were observed only in the condition of 5 dpa at $380{ }^{\circ} \mathrm{C}$. Different evolution mechanisms of the radiation-induced dislocation loops were discussed. Effects of hydrogen and elevated temperature on the microstructural evolution were also investigated. Besides, the formed voids have a further effect on the evolution of dislocation loops.
\end{abstract}

KEY WORDS: Supercritical water-cooled reactor; Austenitic stainless steels; Ion irradiation; Dislocation loops; Hydrogen

\section{Introduction}

Austenitic stainless steels present good creep resistance to higher temperatures coupled with reasonable corrosion/ oxidation resistance, being a candidate structure material

Available online at http://link.springer.com/journal/40195

Li-Ping Guo

guolp@whu.edu.cn

1 Hubei Nuclear Solid Physics Key Laboratory, Key Laboratory of Artificial Micro- and Nano-structures of Ministry of Education and School of Physics and Technology, Wuhan University, Wuhan 430072, China

2 Institute of Applied Physics, Jiangxi Academy of Science, Nanchang 330029, China

3 Center for Electron Microscopy, Wuhan University, Wuhan 430072, China

4 Science and Technology on Reactor Fuel and Materials Laboratory, Nuclear Power Institute of China, Chengdu 610041, China of supercritical water-cooled reactor (SCWR) [1, 2]. Internal structure materials in SCWR cores are exposed to a high neutron flux at high temperature [3], which can induce a loss of corrosion resistance and an increase in the yield stress. The changes in the strength and ductility are mainly due to the accumulation of point defect clusters, mostly Frank loops which hold up the motion of dislocations [4]. Since dislocation loops are important microstructures of irradiation effects in austenitic steels, the understanding of the evolution of dislocation loops is essential to understand radiation-induced changes of macroscopic properties [5, 6].

Hydrogen is one of the important issues, which may affect the microstructure and performance of the reactor materials [7]. Hydrogen atoms are not only generated by nuclear transmutation in fusion and fission reactors, but also generated by environmental sources such as corrosion, radiolytic decomposition and recoil injection, especially in system involving water cooling and moderation [8]. Hydrogen solubility in unirradiated austenitic stainless steels is observed to obey Sieverts' law, which states that 
the concentration in the metal is proportional to the square root of the local hydrogen overpressure. But some data sets produced from light-water reactor irradiations clearly showed that the amount of hydrogen retained in the irradiated samples was far in excess of the equilibrium solubility as determined by Sieverts' law [9]. It was shown that under certain conditions, hydrogen could be stored in irradiated stainless steels at levels strongly in excess of that predicted by Sieverts' law, although hydrogen had a rather high diffusivity in stainless steels. These conditions were first, the availability of hydrogen from various radiolytic and environmental sources and second, the formation of radiation-induced cavities to store hydrogen. The coolant of SCWR is supercritical water, and the working environments of the structure materials in SCWR satisfy these two conditions. Hence, the retention of hydrogen should cause serious problems in structure materials of SCWR. The effect of retained hydrogen on the structure materials in SCWR should not be ignored.

From the point of view of irradiation damage, the effect of hydrogen on radiation-induced defects is a very important problem. However, this effect has not been widely studied in austenitic steels including those used in SCWR. Most of researches on dislocation loops in austenitic steels employed high-energy proton and neutron irradiation $[10,11]$. Unfortunately, in these studies, the retention of hydrogen could be ignored.

AL-6XN stainless steel is one of the candidate structure materials of SCWR because of its excellent property of corrosion resistance in supercritical water environment $[12,13]$. In the present study, AL-6XN stainless steels were irradiated to investigate the nucleation and evolution of dislocation loops. Hydrogen ion irradiation with low energy was performed. High concentration of hydrogen would be retained in the specimen; thus, the effect of retained hydrogen on the evolution of radiation-induced microstructures could also be investigated.

\section{Experimental}

The chemical composition of AL-6XN used in this study is C: $0.013, \mathrm{~S}: 0.005, \mathrm{P}: 0.024, \mathrm{Si}: 0.15, \mathrm{~N}: 0.215, \mathrm{Cu}: 0.34$, Co: 0.35, Mn: 0.39, Mo: 6.20, Cr: 20.39, Ni: 23.75, Fe: 48.17 (wt \%). Specimens for TEM investigation were prepared as disks of $3 \mathrm{~mm}$ in diameter. The bulk materials were first cut into $0.5-\mathrm{mm}$-thick sheets and then thinned to a thickness of about $0.1 \mathrm{~mm}$ by mechanical polishing. Standard TEM disk specimens of $3 \mathrm{~mm}$ in diameter were punched and then further thinned to a thickness of 40-50 $\mu \mathrm{m}$ with silicon carbide paper of grades 800-2000. Finally, these 3-mm disks were electropolished with a MTPA-5 twin-jet electropolishing machine (Shanghai
Jiaotong University, China), with an electrolyte solution of $10 \% \mathrm{HClO}_{4}$ and $90 \% \mathrm{CH}_{3} \mathrm{COOH}$.

Specimens were irradiated with $100 \mathrm{keV} \mathrm{H}_{2}{ }^{+}$ions to $0.5,1,3$ and $5 \mathrm{dpa}$ at 290 or $380{ }^{\circ} \mathrm{C}$ in an ion implanter in the Accelerator Laboratory of Wuhan University. Ions with this energy produce a nearly uniform damage layer in the first $100 \mathrm{~nm}$ from the surface of the specimen with a mean hydrogen/dpa ratio of $4.82 \times 10^{4} \mathrm{appm} / \mathrm{dpa}$, which was calculated by SRIM 2011 with displacement energy $\left(E_{\mathrm{d}}\right)$ of $40 \mathrm{eV}$ as recommended in ASTME521-89 [14]. The irradiated specimens were characterized by TEM to measure the size and number density of dislocation loops and to confirm the type of the dislocation. All the TEM images were taken at the specimen thickness of $\sim 100 \mathrm{~nm}$ (the observation areas were measured by the method of "thickness fringes"). In order to investigate whether the voids were formed, the technique of Fresnel contrast (under-focus, focus and over-focus) was used in this work, which enables the void as small as $1 \mathrm{~nm}$ observed.

\section{Results}

Microstructure of unirradiated AL-6XN stainless steels is shown in Fig. 1. Only some dislocations were found. Figure 2 shows the microstructure of AL-6XN irradiated at $290{ }^{\circ} \mathrm{C}$ and the distribution of dislocation loops. All the images were taken near $\langle 011\rangle$ zone axis at $g=200$ condition. A high number density of black docks and dislocations loops were visible in all the irradiated specimens, and no void was found. Comparing bright and dark fields in the same area, it can be seen that these black docks had typical loop structure under high magnification. These black docks were dislocation loops with small size. At 0.5 ,

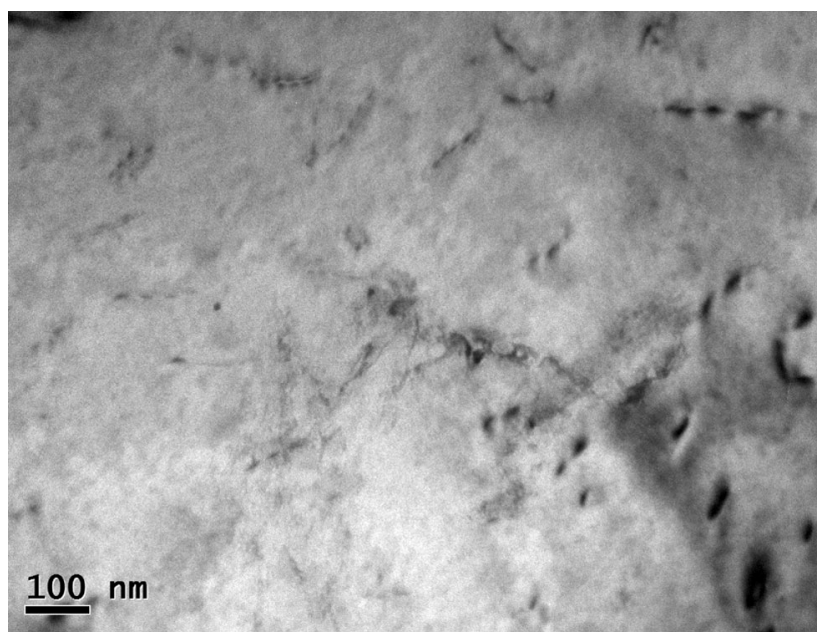

Fig. 1 TEM image of microstructure in unirradiated AL-6XN stainless steels 

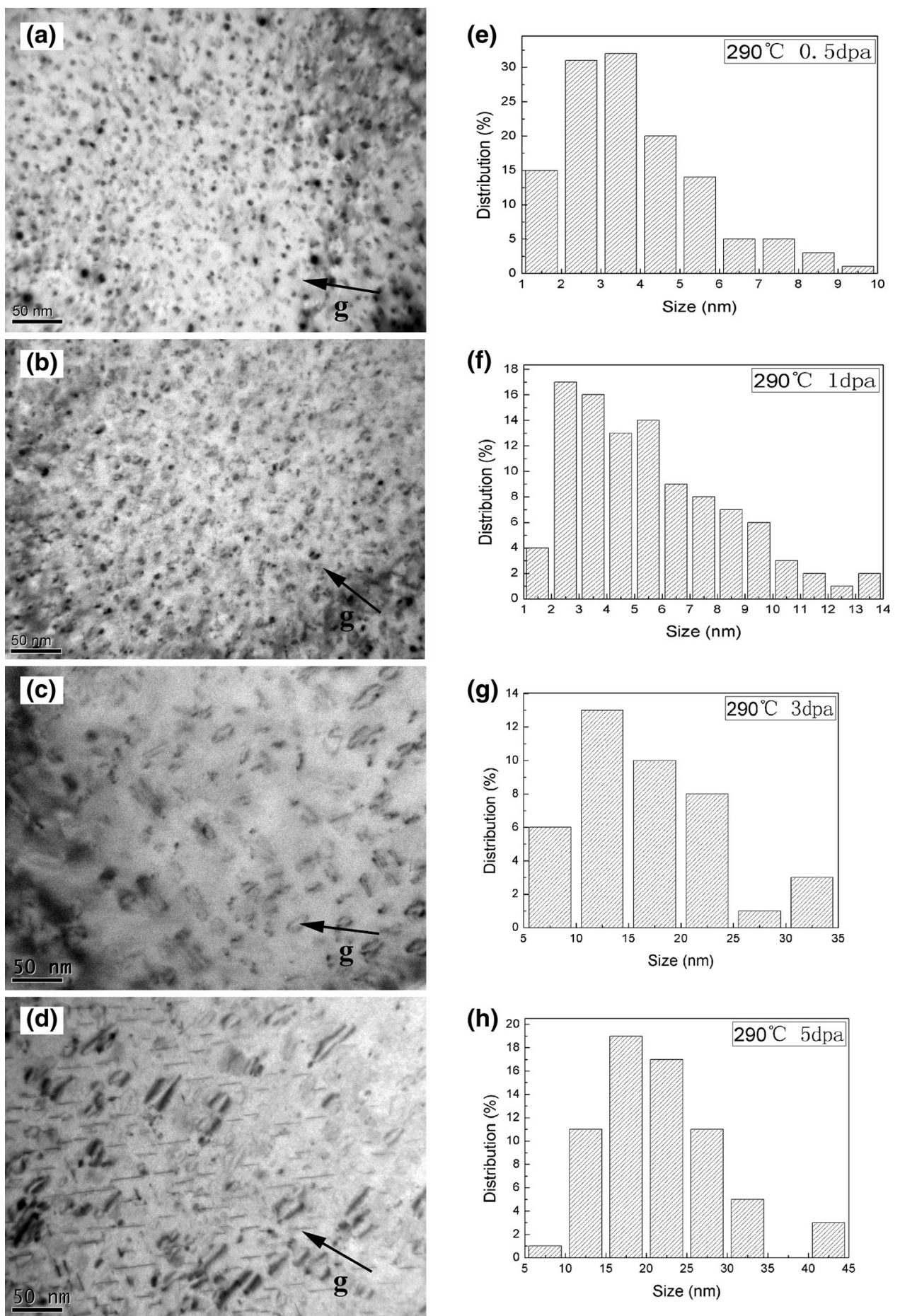

Fig. 2 TEM images of microstructure in AL-6XN irradiated at $290{ }^{\circ} \mathrm{C}$ to 0.5 dpa a, 1 dpa b, 3 dpa c, 5 dpa d, taken near $<011>$ zone axis at $g=200$ condition; $\mathbf{e}, \mathbf{f}, \mathbf{g}, \mathbf{h}$ are the size distribution of the dislocation loops, respectively

1, 3, $5 \mathrm{dpa}$, the number density of the loops was $4.2 \times 10^{22}, 3.4 \times 10^{22}, 6.2 \times 10^{21}, 1.8 \times 10^{21} \mathrm{~m}^{-3}$, and the mean diameter was $3.8,5.6,16.9,21.5 \mathrm{~nm}$, respectively. It indicates that number density of dislocation loops rapidly approached saturation at about $0.5 \mathrm{dpa}$ and then decreased from 0.5 to $5 \mathrm{dpa}$, while mean diameter increased and the proportion of small loops decreased gradually. When irradiated to $5 \mathrm{dpa}$, mean size of the loops might have not saturated yet. From the size distribution of dislocation loops, it could be concluded that the size of dislocation loops became larger with increasing the dose and the size distribution became wider. 

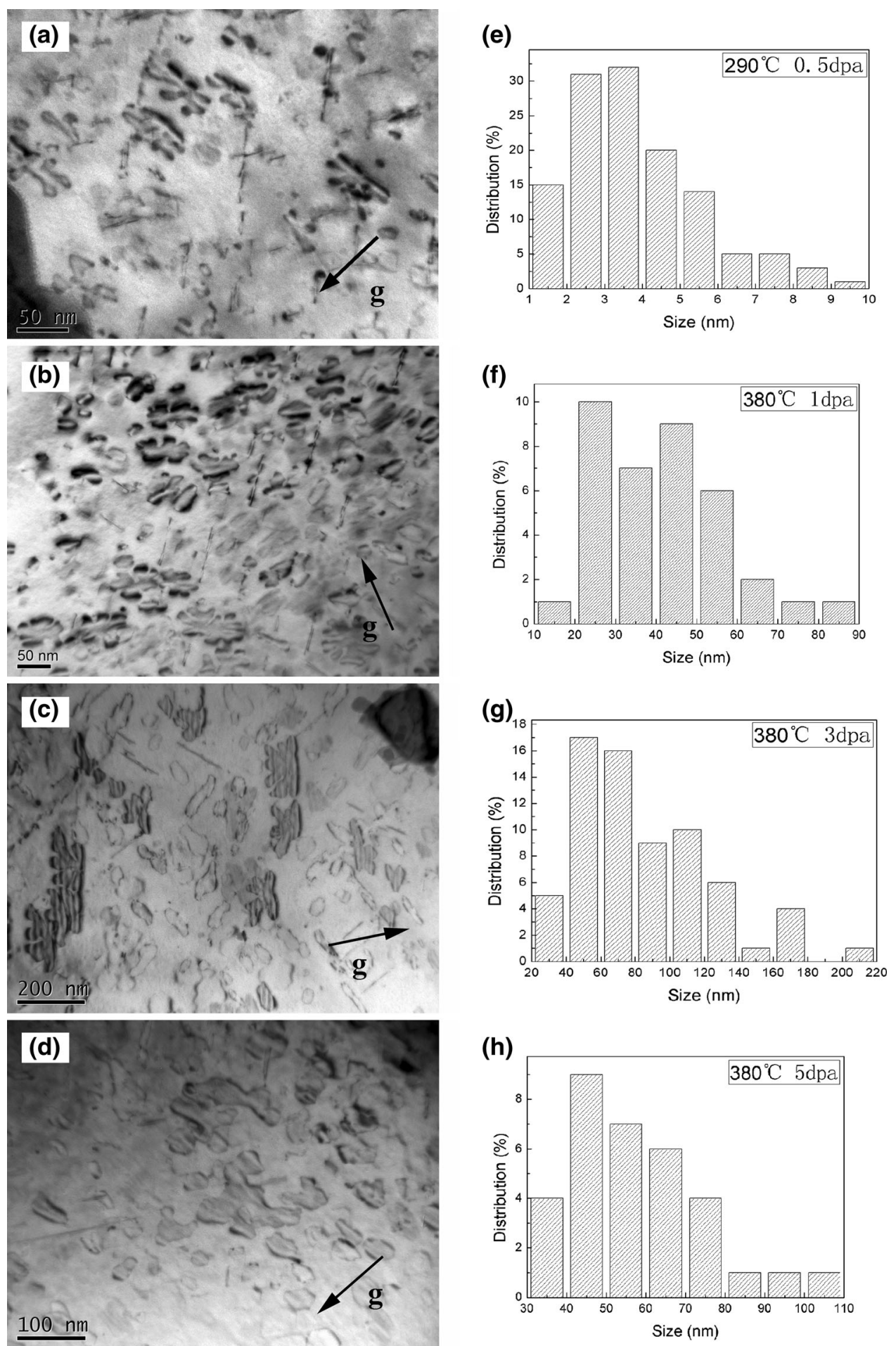

Fig. 3 TEM images of dislocation loops in AL-6XN irradiated at $380{ }^{\circ} \mathrm{C}$ to 0.5 dpa a, 1 dpa b, 3 dpa c, 5 dpa d, taken near $<011>$ zone axis at $g=200$ condition; $\mathbf{e}, \mathbf{f}, \mathbf{g}, \mathbf{h}$ are the size distribution of the dislocation loops, respectively

Figure 3 shows the microstructures of AL-6XN irradiated at $380{ }^{\circ} \mathrm{C}$ and the distribution of dislocation loops. All the images were also taken near the $<011>$ zone axis at $g=200$ condition. Obviously, the radiation-induced dislocation loops at $380{ }^{\circ} \mathrm{C}$ were very different from that at
$290{ }^{\circ} \mathrm{C}$. When irradiated to $0.5,1,3,5 \mathrm{dpa}$, the number densities of the loops were $2.6 \times 10^{21}, 4.1 \times 10^{21}$, $5.5 \times 10^{20}, 2.4 \times 10^{21} \mathrm{~m}^{-3}$, and the mean diameters were $27.1,47.5,85.6,57.2 \mathrm{~nm}$, respectively. The sizes were much larger, and the densities were much smaller than 
those at $290{ }^{\circ} \mathrm{C}$. The loop density approached saturation at $1 \mathrm{dpa}$. At higher doses, there were few small loops to be found. From 1 to $3 \mathrm{dpa}$, the change trend of dislocation loops was similar to that at $290{ }^{\circ} \mathrm{C}$. The loop density reached minimum value and mean diameter reached maximum value at $3 \mathrm{dpa}$. From 3 to $5 \mathrm{dpa}$, the loop density increased again and the size decreased dramatically. From the size distribution of the dislocation loops, the size of the dislocation loops was very large. Some loops were even larger than $200 \mathrm{~nm}$, which were found when irradiated to 3 dpa at $380{ }^{\circ} \mathrm{C}$.

The voids were observed only when irradiated to $5 \mathrm{dpa}$ at $380{ }^{\circ} \mathrm{C}$. Figure 4 shows the microstructure of the voids in this condition. The mean size of the voids was $1.63 \mathrm{~nm}$, and the density was $1.15 \times 10^{23} \mathrm{~m}^{-3}$.

Figure 5 shows different change trends of the loop density and size dependence of the irradiation dose at different temperatures. It is obvious that the dislocation loops at $380{ }^{\circ} \mathrm{C}$ were much larger than those at $290{ }^{\circ} \mathrm{C}$.

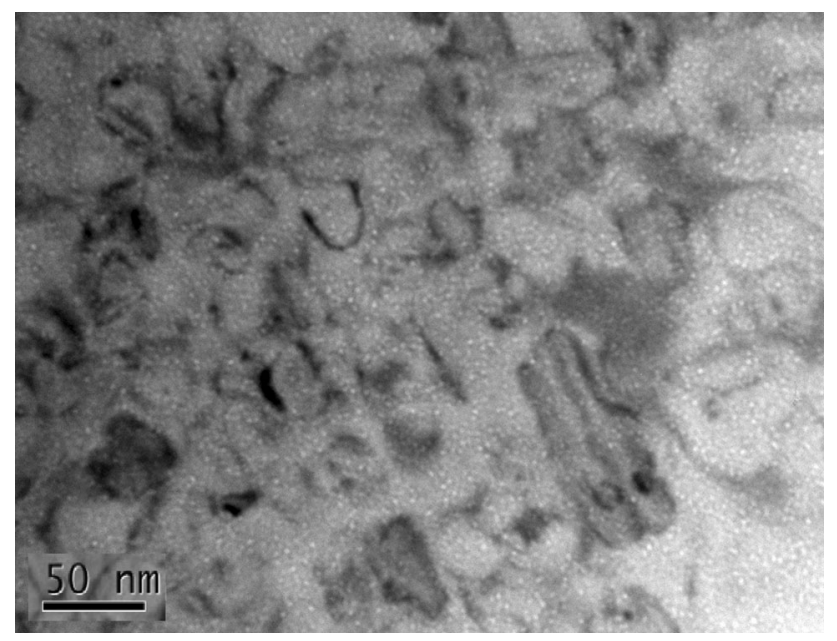

Fig. 4 TEM image of the voids in AL-6XN irradiated at $380{ }^{\circ} \mathrm{C}$ to 5 dpa

(a)

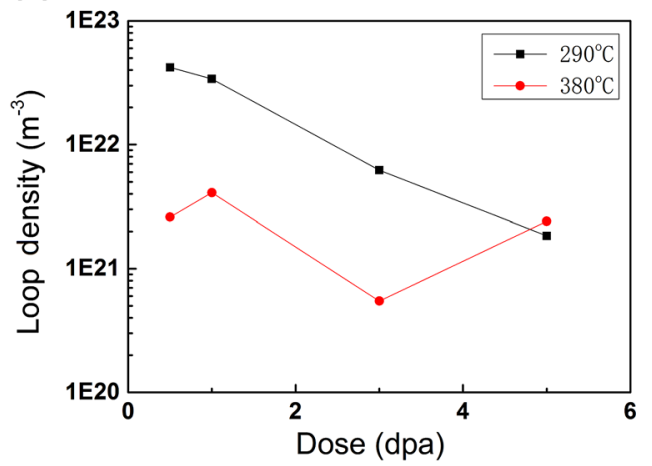

The lower the irradiation temperature, the higher the number density of the dislocation loops observed. And the evolution of the loop density was quite different at different irradiation temperatures. The loop density reached maximum rapidly, which indicates that the nucleation of the dislocation loop was enhanced. The most possible reason for this might be the retention of hydrogen. The different evolution mechanisms of the dislocation loops were discussed below.

The types of the dislocation loops in the present work were also investigated. All the dislocation loops had $1 / 3<111>$ type Burgers vector, which was determined using $g \cdot b=0$ invisibility criterion. The style of the dislocation loops in austenitic steels could be $1 / 3<111>$ Frank-faulted loops or $1 / 2$ $<110>$ perfect loops [12]. The Burgers vector analyses of dislocation loops in all the specimens were using $g=200$, $\overline{1} 1 \overline{1}$ and $\overline{1} \overline{1} 1$ near the $<011>$ zone axis. Figure 6 shows that each of the dislocation loops appeared in these three $g$ micrographs taken in the same area, which indicated that only $1 / 3<111>$ Frank-faulted loops existed.

\section{Discussion}

The style of the loops in austenitic steels only contains $1 / 3$ $<111>$ Frank-faulted loops and $1 / 2<110>$ perfect loops [15]. In most of the researches, only Frank loops were found in irradiated austenitic steels [4, 11, 16-18]. Only a few researches reported perfect loops [19]. In the present study, TEM microscopy examination indicates that dislocation loops were the dominant radiation-induced defects and only $1 / 3<111>$ Frank-faulted loops were observed. Some studies showed that the majority of Frank loops in irradiated austenitic steels were interstitial in nature [16-18]. A few authors considered that Frank loops could be either interstitial or vacancy $[20,21]$. In our view, since the mobility of interstitials is three orders of magnitude

(b)

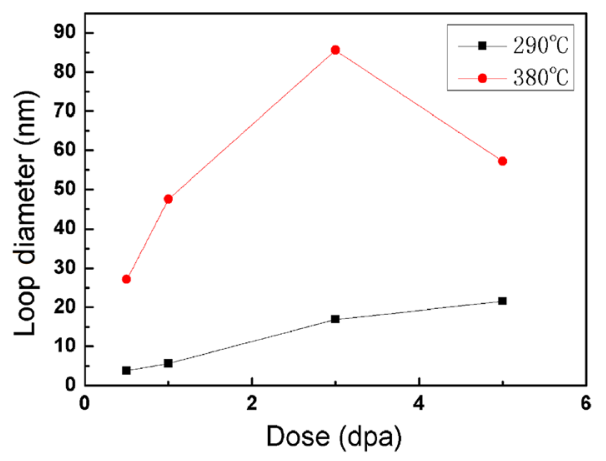

Fig. 5 Loop density a and mean loop diameter $\mathbf{b}$ dependence of irradiation dose 


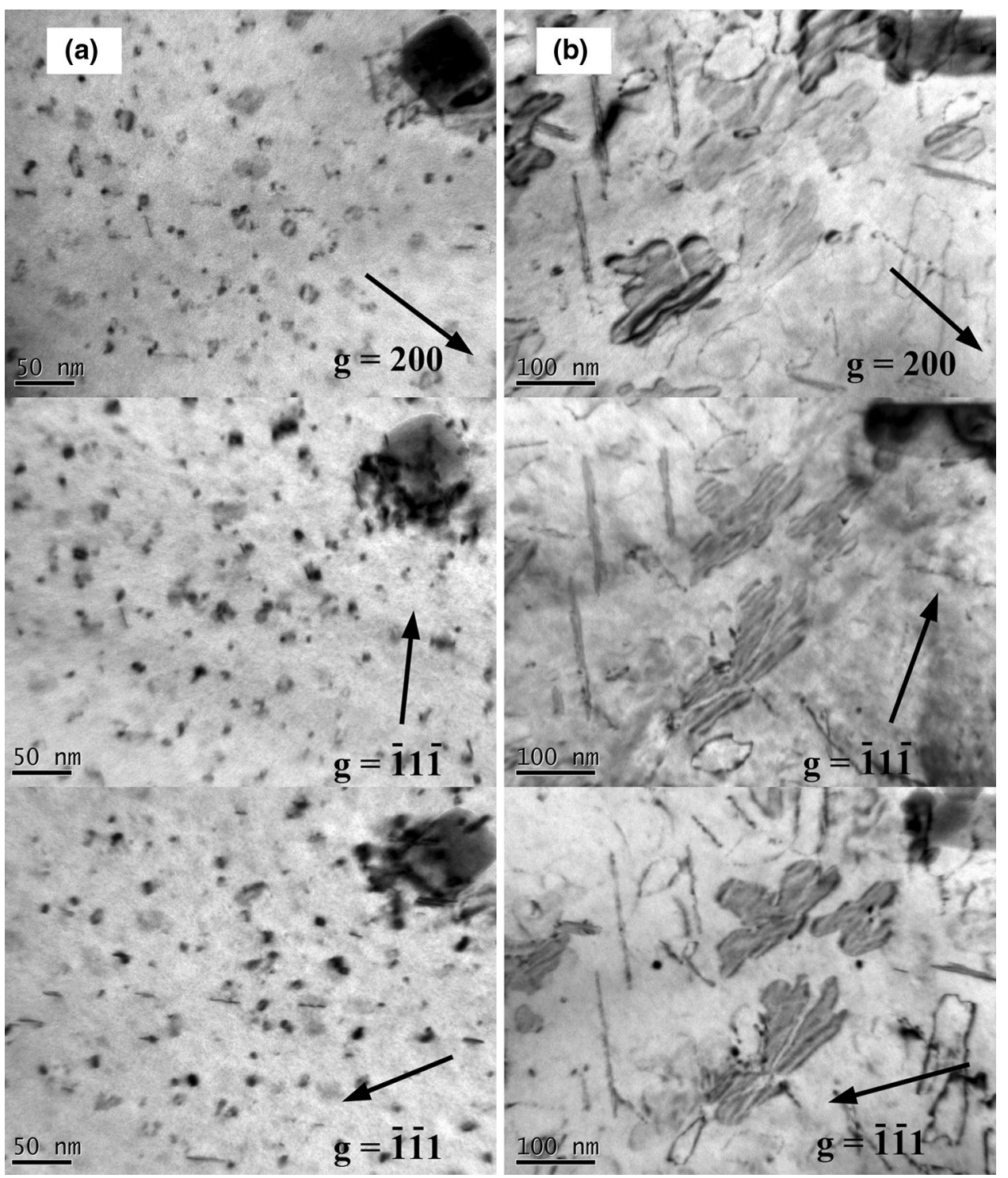

Fig. 6 TEM images of the dislocation loops in specimens irradiated to 3 dpa at $290{ }^{\circ} \mathrm{C} \mathbf{a}, 380{ }^{\circ} \mathrm{C} \mathbf{b}$, using $g=200, \overline{1} 1 \overline{1}$ and $\overline{1} 11$ near the $<011>$ zone axis

higher than that of vacancies [22], the Frank loops should be interstitial type [4].

$\mathrm{Xu}$ et al. [22] investigated the nucleation and growth of interstitial-type dislocation loops by neutron irradiations with improved temperature control. They found that the loops were nucleated directly by the defect production process in the cascade zone during irradiation, not by the reaction among the freely migrating point defects in the matrix. Another research [23] about $\mathrm{Ni}^{+}$ion irradiation in austenitic alloy indicated that the interstitial-type dislocation loops were nucleated in the interstitial-rich zone. Ion radiation-induced dislocation loops may have the same nucleation mechanism as interstitial-type dislocation loops induced by neutron irradiation.
The data in Ref. [10, 11] of austenitic stainless steels irradiated by high-energy proton and neutron reveal that: In proton-irradiated alloy, the loop size and density rapidly increase with dose up to $1 \mathrm{dpa}$, approaching saturation between 3 and $5 \mathrm{dpa}$; in neutron-irradiated alloys, the loop densities are saturate around $3 \mathrm{dpa}$ and the dose for saturation of loop size is less clear, but appears to be between 4 and 5 dpa. As all known, irradiation can produce large numbers of interstitials and vacancies. Most of these point defects are annihilated finally. Only a few of these point defects are survived. Interstitials can move easily than vacancies. Interstitial atoms aggregate to form interstitialtype dislocation loops. With increasing the dose, the interstitial dislocation loops will grow gradually large by 
absorbing interstitials and the size will saturate finally. Loop unfaulting and interstitial cluster diffusion can result in the loss of loops. When the nucleation and loss of loops reach balance, the loop density approaches saturation [10]. Compared with these studies, the evolution of dislocation loops in our study is very different. The main reason for the large difference seems due to the effect of retained hydrogen. In studies of high-energy proton and neutron irradiations, the concentration of hydrogen could be ignored. But in the present study, hydrogen/dpa ratio in observed area of the specimens is very high. The retention and accumulation of hydrogen might have a great effect on the evolution of microstructures. Hydrogen can be trapped by vacancy clusters to form H-vacancy complexes [24], and therefore, more interstitial atoms would be retained. As a result, the nucleation and growth of interstitial-type dislocation loops are enhanced.

In the condition of irradiation at $290{ }^{\circ} \mathrm{C}$, because of hydrogen enhancing the nucleation of dislocation loops, loop density rapidly approached saturation at $0.5 \mathrm{dpa}$. Then with increasing the dose, dislocation loops grew larger by absorbing interstitials and nearby small loops [25], so the mean size increased and the density decreased. With the accumulation of defects, dislocation loops may saturate at higher dose.

In the condition of irradiation at $380{ }^{\circ} \mathrm{C}$, the evolution of loops was quite different from that at $290{ }^{\circ} \mathrm{C}$ : The dislocation loops had much larger size and smaller density and the loop density saturated at higher dose $(1 \mathrm{dpa})$. These can be explained by two reasons. Firstly, the elevated temperature can affect the microstructure evolution, especially the overall sink strength [10]. It can promote the migration and reaction of defects, leading to form large-size and lowdensity defect clusters. Secondly, H-vacancy complexes were unstable above $350{ }^{\circ} \mathrm{C}$ [26], and hydrogen can easily escape from vacancies and small clusters during irradiation. So the enhancing effect on nucleation of dislocation loops was weakened.

The most abnormal result was that the mean loop diameter came to maximum value when irradiated to $3 \mathrm{dpa}$ at $380{ }^{\circ} \mathrm{C}$ and then decreased with increasing the dose; meanwhile, the loop density increased again. As Fig. 4 shows, in the process from 3 to $5 \mathrm{dpa}$, the voids were nucleated in large amounts. Voids are trap sites of vacancies, leading to an increase in vacancy loss to sinks; thus, the partitioning of interstitials to form loops increased. Large-size dislocation loops can absorb vacancy defects to shrink in size $[27,28]$. So the loop density increased again, and the size decreased dramatically. It indicates that the nucleation and growth of voids have a great effect on the evolution of dislocation loops.

No voids were observed at $5 \mathrm{dpa}$ in austenitic stainless steels irradiated by high-energy proton and neutron $[10,11]$.
In the present work, voids were observed when irradiated to $5 \mathrm{dpa}$ at $380{ }^{\circ} \mathrm{C}$. This reflects that the radiation-induced swelling is aggravated by the retention of hydrogen. The injection of hydrogen can promote the nucleation of voids [10, 26, 29], and H-vacancy complexes can promote voids growth under further irradiation [30].

\section{Conclusions}

The nucleation and evolution of dislocation loops were investigated in AL-6XN stainless steels irradiated at different doses and different temperatures. All the dislocation loops had $1 / 3<111>$ type Burgers vector, and they might be interstitial type.

The evolution of dislocation loops was greatly influenced by elevated temperature and the injection of hydrogen. The elevated temperature could promote the migration and interaction of defects, leading to form largesize and small-density dislocation loops. Hydrogen can enhance the nucleation and growth of interstitial-type dislocation loops by forming H-vacancy complexes. Hydrogen can also enhance the nucleation and growth of voids. And the formed voids have a further effect on the evolution of dislocation loops.

Acknowledgments The financial supports from the International Science and Technology Cooperation Program of China (No. 2015DFR60370) and the National Natural Science Foundation of China (Nos. 11275140 and U1532134) are gratefully acknowledged.

\section{References}

[1]. C.R.F. Azevedo, Eng. Fail. Anal. 18, 1943 (2011)

[2]. L.F. Zhang, Y.C. Bao, R. Tang, Nucl. Eng. Des. 249, 180 (2012)

[3]. C.W. Sun, R. Hui, W. Qu, S. Yick, Corros. Sci. 51, 2508 (2009)

[4]. A. Etienn, M. Hernández-Mayoral, C. Genevois, B. Radiguet, P. Pareige, J. Nucl. Mater. 400, 56 (2010)

[5]. F.F. Luo, Z. Yao, L.P. Guo, J.P. Suo, Y.M. Wen, Mater. Sci. Eng., A 607, 390 (2014)

[6]. D. Rodney, G. Martin, Y. Bréchet, Mater. Sci. Eng., A 309-310, 198 (2001)

[7]. G.S. Was, S.M. Bruemmer, J. Nucl. Mater. 216, 326 (1994)

[8]. G.D. Tolstolutskaya, V.V. Ruzhytskiy, I.E. Kopanets, S.A. Karpov, V.V. Bryk, V.N. Voyevodin, F.A. Garner, J. Nucl. Mater. 356, 136 (2006)

[9]. F.A. Garner, E.P. Simonen, B.M. Oliver, L.R. Greenwood, M.L. Grossbeck, W.G. Wolfer, P.M. Scott, J. Nucl. Mater. 356, 122 (2006)

[10]. J. Gan, G.S. Was, J. Nucl. Mater. 297, 161 (2001)

[11]. G.S. Was, J.T. Busby, T. Allen, E.A. Kenik, A. Jenssen, S.M. Bruemmer, J. Gan, A.D. Edwards, P.M. Scott, P.L. Andreson, J. Nucl. Mater. 300, 198 (2002)

[12]. K.J. Yin, S.Y. Qiu, R. Tang, X.F. Hong, L.F. Zhang, Q. Zhang, J. Chin. Soc. Corros. Prot. 32, 375 (2012). (in Chinese)

[13]. J.J. Yu, G.M. Lu, S.Z. Shang, J.G. Yu, Corros. Prot. 32, 12 (2011) 
[14]. Standard Practice for Neutron Radiation Damage Simulation by Charged particle Irradiation, in ASTM Designation E 521-89, Annual Book of ASTM Standards, vol. 12.02 (American Society for Testing and Materials, Philadelphia, PA, 1989), p. D-9

[15]. D. Hull, D.J. Bacon, Introduction to Dislocations (ButterworthHeinemann, Oxford, 2001)

[16]. N. Hashimoto, E. Wakai, J.P. Robertson, J. Nucl. Mater. 273, 95 (1999)

[17]. E.H. Lee, J.D. Hunn, T.S. Byun, L.K. Mansur, J. Nucl. Mater. 280, 18 (2000)

[18]. T.S. Byun, E.H. Lee, J.D. Hunn, J. Nucl. Mater. 321, 29 (2003)

[19]. T. Sawai, Y. Kitsunai, S. Saito, K. Kikuchi, J. Nucl. Mater. 356, 118 (2006)

[20]. D.J. Edwards, E.P. Simonen, F.A. Garner, L.R. Greenwood, B.M. Oliver, S.M. Bruemmer, J. Nucl. Mater. 317, 32 (2003)

[21]. R. Stoenescu, R. Schaublin, D. Gavillet, N. Baluc, J. Nucl. Mater. 360, 186-195 (2007)

[22]. Q. Xu, N. Yoshida, T. Yoshiie, J. Nucl. Mater. 258-263, 1730 (1998)
[23]. N. Sakaguchi, H. Kinoshita, S. Watanabe, Y. Sueishi, N. Akasaka, H. Takahashi, J. Nucl. Mater. 382, 197 (2008)

[24]. K. Ono, T. Kino, S. Furuno, K. Hojou, K. Izui, K. Mizuno, K. Ito, J. Nucl. Mater. 179-181, 978 (1991)

[25]. Y.N. Huang, F.R. Wan, Z.J. Jiao, Acta Phys. Sin. 60, 036802 (2011)

[26]. T. Ishizakil, Q. Xu, T. Yoshiie, S. Nagata, Mater. Trans. 45, 9 (2004)

[27]. F.R. Wan, X.F. Zhu, J.M. Xiao, Y. Yuan, Acta Phys. Sin. 39, 1093 (1990)

[28]. Q. Xu, H. Watanabe, N. Yoshida, J. Nucl. Mater. 233-237, 1057 (1996)

[29]. S.N. Jiang, F.R. Wan, Y. Long, J.C. He, P.P. Liu, Acta Metall. Sin. (Engl. Lett.) 26, 303 (2013)

[30]. T. Yoshiie, K. Sato, X. Cao, Q. Xua, M. Horiki, T.D. Troev, J. Nucl. Mater. 429, 185 (2012) 